\title{
Recovery from Out-of-Hospital Cardiopulmonary Arrest Due to Type A Acute Aortic Dissection: A Case Report
}

\author{
Yoko Sugawara1, Tomohiro Kurihara', Satoshi Ohtsubo ${ }^{2}$, Masanori Takamatsu' ${ }^{2}$, Kenichiro Sasao', \\ Motojiro Takebe $^{1}$, Shiho Irino' ${ }^{1}$, Mirai Takahashi' ${ }^{1}$ Takashi Hirotani2 ${ }^{2}$ Kazuhiko Sekine1* \\ ${ }^{1}$ Department of Emergency and Critical Care Medicine, Tokyo Saiseikai Central Hospital, Tokyo, Japan \\ ${ }^{2}$ Department of Cardiovascular Surgery, Tokyo Saiseikai Central Hospital, Tokyo, Japan \\ Email: ^ysato.luna@gmail.com
}

How to cite this paper: Sugawara, Y., Kurihara, T., Ohtsubo, S., Takamatsu, M., Sasao, K., Takebe, M., Irino, S., Takahashi, M., Hirotani, T. and Sekine, K. (2016) Recovery from Out-of-Hospital Cardiopulmonary Arrest Due to Type A Acute Aortic Dissection: A Case Report. Case Reports in Clinical Medicine, 5, 505-510.

http://dx.doi.org/10.4236/crcm.2016.511064

Received: October 19, 2016

Accepted: November 26, 2016

Published: November 29, 2016

Copyright $\odot 2016$ by authors and Scientific Research Publishing Inc.

This work is licensed under the Creative Commons Attribution International

License (CC BY 4.0).

http://creativecommons.org/licenses/by/4.0/

c) (i) Open Access

\begin{abstract}
Case: A 55-year-old man without past medical histories suffering from back pain for two weeks was successfully resuscitated from an 8-min cardiopulmonary arrest (CPA) and was brought to our hospital by ambulance. Computed tomography demonstrated type A acute aortic dissection (AAAD) with brachiocephalic artery occlusion. After admission, Glasgow Coma Scale score improved to E1VTM4, and voluntary movement was noted only in the right limbs. Outcome: The patient underwent emergency grafting of the ascending aorta and innominate artery under deep hypothermic circulatory arrest. After surgery, the patient recovered with mild disorientation and left hemiplegia. Magnetic resonance imaging of the head revealed no large infarction but revealed multiple acute ischemic changes. One year later, the patient demonstrated independent walk and successfully returned to work life. Conclusions: Immediate resuscitation and surgery resulted in good recovery from CPA after AAAD.
\end{abstract}

\section{Keywords}

Aortic Branch Artery Occlusion, Cerebral Ischemia, Malperfusion, Prognosis, Surgical Indication

\section{Introduction}

Type A acute aortic dissection (AAAD) requires emergency surgery as definitive treatment with a mortality rate of more than $40 \%$ after onset [1]. Poor prognosis has been reported with cardiopulmonary arrest (CPA) [2], aortic branch occlusion [3] [4] [5] 
[6], severe consciousness disturbance [4], and cerebral vascular disorders (CVD) [4] in the preoperative period. We report a case of $A A A D$, requiring emergency surgery and recovering after out-of-hospital CPA with good neurological outcome.

\section{Case Report}

A 55-year-old man without past medical histories suffering from back pain for 2 weeks was brought to our hospital by ambulance because of dyspnea at his office. Following were the patient's vital signs: Glasgow Coma Scale (GCS) score, 15; respiratory rate (RR), 36/min; pulse, 60/min; blood pressure (BP), 110/54 $\mathrm{mmHg}$; and $\mathrm{SpO}_{2}, 60 \%$ (room air) at the scene (Normal vital sign ranges are; GCS 15, RR 12 - 18/min, pulse 60 100/min, BP 120 - 90/80 - 60 mmHg, $\mathrm{SpO}_{2}$ 96\% - 100\% (room air)). However, vital signs deteriorated 3 min after ambulance arrival (GCS score, 3 and BP, immeasurable). Breathing ceased and pulseless electrical activity (PEA) was observed 9 min after ambulance arrival, and cardiopulmonary resuscitation (CPR) by chest compression and mask ventilation were started immediately by the emergency medical service (EMS). Seventeen minutes after ambulance arrival, the patient was resuscitated successfully with return of spontaneous circulation (ROSC) and respiration during transport and was brought to our emergency room (ER) 23 min after ambulance arrival. The patient had widened mediastinum, severe pulmonary edema, bilateral pulmonary effusion on chest X-ray (Figure 1(a)), severe aortic regurgitation and no pericardial effusion on echocardiography. Whole-body computed tomography (CT) demonstrated no obvious intracranial hemorrhage (Figure $1(\mathrm{~b})$ ) but AAAD from the ascending aorta to the bilateral common iliac arteries with brachiocephalic and right carotid artery occlusion by false lumen thrombosis (Figures $1(\mathrm{c})$-(f)).

Forty minutes after ER arrival, GCS score improved to E1VTM4, and voluntary movement occurred only in the right limbs. Because a good prognosis seemed possible, emergency surgery for AAAD was performed, despite the predisposed risks. Under deep hypothermic circulatory arrest at rectal temperature of $20^{\circ} \mathrm{C}$, emergency grafting of the ascending aorta and innominate artery was performed $3 \mathrm{~h} 48 \mathrm{~min}$ after ER arrival. For revascularization of the true lumen in the right carotid artery, the distal innominate artery at the bifurcation of the right subclavian and right common carotid arteries was transected and the thrombus was extracted from the false lumen of the proximal carotid artery. The AAAD did not extend to the root of the left carotid and bilateral coronary arteries. On postoperative day 3 , after discontinuing all sedatives, the patient was extubated with restoration of consciousness (GCS score, E4V4M6) and left hemiplegia. There were no hemorrhagic intracranial lesions on head CT on postoperative day 5, and high-intensity spots and local areas were found in the anterior parietal lobes on head diffusion-weighed magnetic resonance imaging (MRI) on postoperative day 11 (Figure 2(a), Figure 2(b)). Large infarction was absent, but multiple acute ischemic changes were noted after the occlusion of the right carotid artery. The patient was able to walk for 30 meter with a walking-stick and mild disorientation. He was transferred to a rehabilitation hospital on postoperative day 25 . The cerebral and overall 

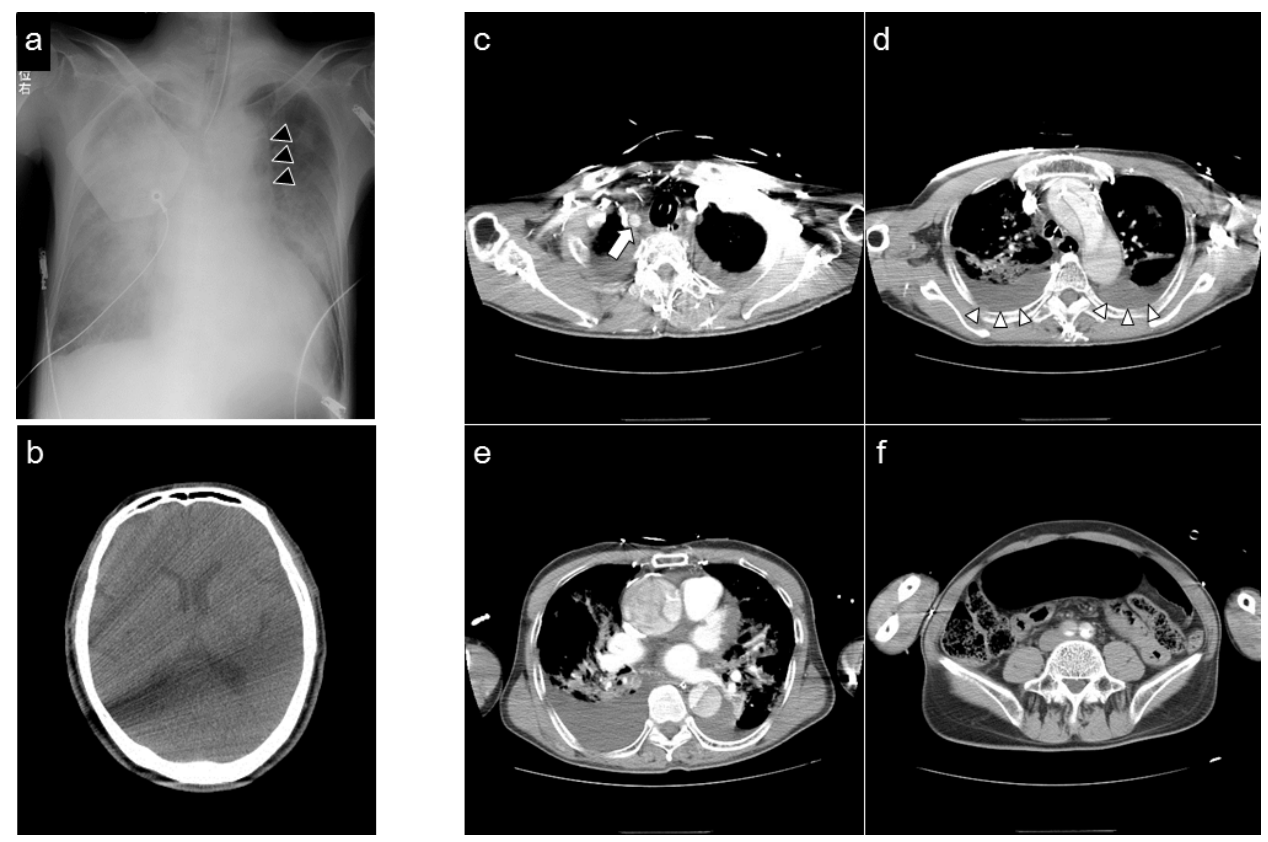

Figure 1. Preoperative radiological examinations. Chest X-ray and enhanced computed tomography (CT) scans showed widened mediastinum (black triangles), severe pulmonary edema (a), and bilateral pulmonary effusion (white triangles). There was no evidence of intracranial hemorrhage or large cerebral infarction on plain head CT (b). Type A acute aortic dissection from the ascending aorta to bilateral common iliac arteries with the brachiocephalic and right carotid artery occlusion (white arrow) by false lumen thrombosis on enhanced CT scans (c)-(f).
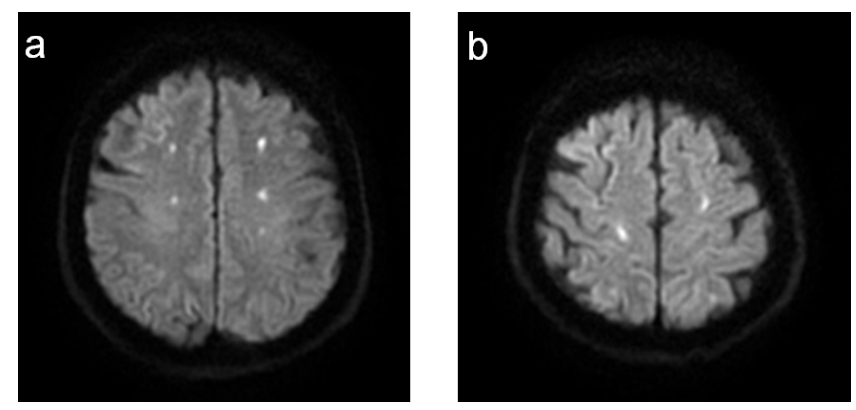

Figure 2. Postoperative diffusion-weighed magnetic resonance imaging demonstrates highintensity spots (a), (b) and areas (b) in both anterior parietal lobes on postoperative day 11 . There was no large infarction, but multiple acute ischemic changes were noted after right carotid artery occlusion associated with type A acute aortic dissection.

performance category (CPC and OPC) was grade 2 at hospital discharge. One year later, he was able to walk independently, supported by a walking-stick, and return to work (OPC1/CPC1).

\section{Discussion}

There are two important points in this case. First, the AAAD patient was quickly resuscitated from an 8-min cardiac arrest probably due to severe hypoxia and pulmonary edema. Next, immediate surgery after ROSC resulted in good recovery of AAAD because 
large cerebral infarction had been avoided.

Poor prognostic factors after surgical treatment of AAAD include cardiopulmonary arrest [2], severe disturbance of consciousness [4], and cerebrovascular disorder [4] in the preoperative period. Emergency surgery in patients with those risk factors usually is avoided because of high mortality and morbidity. One reason, avoiding surgery, is that anticoagulant use during intraoperative extracorporeal circulation may promote hemorrhagic cerebral infarction or posttraumatic intracranial hemorrhage [5]. Regarding our patient, despite three preoperative poor prognostic factors, the recovery suggests that the effects of these factors remained minimal.

Regarding the timing of surgery for AAAD, even in patients with CVD, the postoperative outcome was not affected by early operation [4] [7]. Moreover, some cases fully recovered by immediate surgery within 3 hour after ER arrival [5]. Our patient showed left hemiplegia perioperatively, which was not aggravated by immediate surgery, revealing minimal cerebral ischemic changes on MRI. Considering the duration of treatment by tissue-plasminogen activator for acute ischemic stroke, anticoagulant use by intraoperative extracorporeal circulation may not be harmful during immediate surgery for AAAD complicated by cerebral malperfusion.

Few cases of out-of-hospital CPA after AAAD have been reported worldwide except in Japan [8] [9] [10]. Four patients recovered from in- and out-of-hospital CPA after AAAD by emergency surgery (Table 1) [8] [9] [10]. Three patients received immediate CPR from healthcare providers, whereas one patient was given CPR by a swimming

Table 1. Past cases recovered after cardiopulmonary arrest because of type A acute aortic dissection.

\begin{tabular}{|c|c|c|c|c|c|c|c|c|c|c|c|c|}
\hline $1[8]$ & Kurimoto & 2002 & 71 & Female & Prehospital & $\begin{array}{l}\text { By a } \\
\text { swimming } \\
\text { instructor }\end{array}$ & NA & $\begin{array}{c}\text { Cardiac } \\
\text { tamponade }\end{array}$ & $45 \mathrm{~min}$ & $\begin{array}{l}\text { Coma, involuntary } \\
\text { limb movement } \\
\text { in response to } \\
\text { noxious stimuli }\end{array}$ & NA & Recovered \\
\hline $2[9]$ & Saito & 2007 & 80 & Male & ICU & $\begin{array}{c}\text { By a cardiac } \\
\text { surgeon }\end{array}$ & PEA & $\begin{array}{l}\text { Cardiac } \\
\text { tamponade }\end{array}$ & NA & $\begin{array}{l}\text { Voluntary limb } \\
\text { movement in } \\
\text { response to } \\
\text { verbal stimuli }\end{array}$ & NA & $\begin{array}{l}\text { Recovered with } \\
\text { left hemiplegia }\end{array}$ \\
\hline 4 & Our case & 2015 & 50 & Male & Prehospital & $\begin{array}{l}\text { By an EMS } \\
\text { personnel }\end{array}$ & PEA & $\begin{array}{c}\text { Unknown } \\
\text { (hypoxia or } \\
\text { transient aortic } \\
\text { occlusion by flap) }\end{array}$ & $8 \min$ & $\begin{array}{l}\text { GCS E1VTM4, } \\
\text { left hemiplegia }\end{array}$ & $3.5 \mathrm{~h}$ & Recovered \\
\hline
\end{tabular}

Abbreviations: CA: cardiac arrest, CPR: cardiopulmonary resuscitation, EMS: emergency medical system, ER: emergency room, ICU: intensive care unit, GCS: Glasgow coma scale, NA: not available, OR: operating room, PEA: pulseless electrical activities. 
instructor who was well-trained in CPR procedures and also by healthcare providers. Thus, a witness, prompt high-quality CPR, and relieving CPA cause, including resuscitative pericardiocentesis if necessary, are considered essential for recovery from CPA after AAAD. A short duration until ROSC generally is favorable for predicting neurological outcome, but surprisingly, the duration varies between 2 and $45 \mathrm{~min}$ in the prior reports (Table 1). Therefore, the time window for favorable outcomes depends on the cause of CPA and subsequent resuscitative procedures after AAAD. After all, all patients had improved consciousness and response or limb movement to noxious stimuli within several hours after ROSC. Several factors, such as a witness, immediate highquality CPR, quick removal of CPA cause, and neurologically-recovering symptoms in the early phase after ROSC, are necessary for recovery from CPA after AAAD. Conclusively, immediate resuscitation and surgery may improve an outcome of ROSC patients after AAAD with the several factors above.

\section{Conclusion}

We report a good recovery from CPA after AAAD by immediate resuscitation and surgery.

\section{Acknowledgements}

This case report was presented at the $64^{\text {th }}$ KANTO Japanese association for acute medicine 2014, Yokohama, Kanagawa, Japan. The patient gave the authors his consent for the case report to be published.

\section{References}

[1] Krüger, T., Conzelmann, L.O., Bonser, R.S., Borger, M.A., Czerny, M., Wildhirt, S., Carrel, T., Mohr, F.W., Schlensak, C. and Weigang, E. (2012) Acute Aortic Dissection Type A. British Journal of Surgery, 99, 1331-1344. http://dx.doi.org/10.1002/bjs.8840

[2] Meron, G., Kürkciyan, I., Sterz, F., Tobler, K., Losert, H., Sedivy, R., Laggner, A.N. and Domanovits, H. (2004) Non-Traumatic Aortic Dissection or Rupture as Cause of Cardiac Arrest: Presentation and Outcome. Resuscitation, 60, 143-150. http://dx.doi.org/10.1016/j.resuscitation.2003.10.005

[3] Oderich, G.S. and Panneton, J.M. (2002) Acute Aortic Dissection with Side Branch Vessel Occlusion: Open Surgical Options. Seminar in Vascular Surgery, 15, 89-96.

http://dx.doi.org/10.1053/svas.2002.33087

[4] Tanaka, H., Okada, K., Yamashita, T., Morimoto, Y., Kawanishi, Y. and Okita, Y. (2005) Surgical Results of Acute Aortic Dissection Complicated with Cerebral Malperfusion. The Annals of Thoracic Surgery, 80, 72-76. http://dx.doi.org/10.1016/j.athoracsur.2004.12.049

[5] Estrera, A.L., Garami, Z., Miller, C.C., Porat, E.E., Achouh, P.E., Dhareshwar, J., Meada, R., Azizzadeh, A. and Safi, H.J. (2006) Acute Type A Aortic Dissection Complicated by Stroke: Can Immediate Repair Be Performed Safely? The Journal of Thoracic and Cardiovascular Surgery, 132, 1404-1408. http://dx.doi.org/10.1016/j.jtcvs.2006.07.026

[6] Oderich, G.S., Panneton, J.M., Bower, T.C., Ricotta 2nd, J.J., Sundt 3rd, T.M., Cha, S. and Gloviczki, P. (2008) Aortic Dissection with Aortic Side Branch Compromise: Impact of Malperfusion on Patient Outcome. Perspectives in Vascular Surgery and Endovascular 
Therapy, 20, 190-200. http://dx.doi.org/10.1177/1531003508320227

[7] Nakamura, Y., Tagusari, O., Ichikawa, Y. and Morita, A. (2011) Impact of Immediate Aortic Repair on Early and Midterm Neurologic Status in Patients with Acute Type A Aortic Dissection Complicated by Cerebral Malperfusion. The Annals of Thoracic Surgery, 92, 336-338. http://dx.doi.org/10.1016/j.athoracsur.2010.12.065

[8] Kurimoto, Y., Morishita, K., Narimatsu, E., Asai, Y. and Abe, T. (2002) Satisfactory Recovery after 45 Minutes of Resuscitation in Acute Aortic Dissection. Critical Care Medicine, 30, 2030-2031. http://dx.doi.org/10.1097/00003246-200209000-00012

[9] Saito, H., Eguchi, S., Maruyama, Y., Kansaku, R., Takae, H. and Sagawa, N. (2007) Preoperative Pulseless Electrical Activity of Acute Type A Aortic Dissection; Report of a Case. Kyobu Geka, 60, 1192-1195. (In Japanese)

[10] Fujii, K., Miyatake, S., Ishiyama, M., Ooki, M., Tomioka, H., Kase, K. and Kobayashi, K. (2014) A Case of Cariac Tamponade Complicating Acute Type A Aortic Dissection for Which a Small Amount of Pericardial Drainage Was Effective. Journal of Japanese Association for Acute Medicine, 25, 792-796. (In Japanese)

Submit or recommend next manuscript to SCIRP and we will provide best service for you:

Accepting pre-submission inquiries through Email, Facebook, LinkedIn, Twitter, etc. A wide selection of journals (inclusive of 9 subjects, more than 200 journals)

Providing 24-hour high-quality service

User-friendly online submission system

Fair and swift peer-review system

Efficient typesetting and proofreading procedure

Display of the result of downloads and visits, as well as the number of cited articles

Maximum dissemination of your research work

Submit your manuscript at: http://papersubmission.scirp.org/

Or contact crcm@scirp.org 